\title{
A DOENÇA DE CHAGAS E A FACULDADE DE MEDICINA DE RIBEIRÃO PRETO: OS PRIMEIROS TEMPOS
}

\author{
THE FACULTY OF MEDICINE OF RIBEIRAO PRETO AND CHAGAS’ DISEASE: THE EARLY TIMES
}

\author{
Ricardo Brandt de Oliveira
}

Docente. Departamento de Clínica Médica. Faculdade de Medicina de Ribeirão Preto-USP.

Correspondência: Ricardo Brandt de Oliveira. Departamento de Clínica Médica. Faculdade de Medicina de Ribeirão Preto-USP. Av. Bandeirantes, 3900. CEP 14048-900 Ribeirão Preto, São Paulo, Brasil. Telefone (16) 602-2457. Fax: (16)633-6695. e-mail: rbdolive@fmrp.usp.br

OLIVEIRA RB. A doença de Chagas e a Faculdade de Medicina de Ribeirão Preto: os primeiros tempos. Medicina, Ribeirão Preto, 33: 338-340, ,jul./set. 2000.

RESUMO: Os estudos pioneiros, sobre a doença de Chagas, realizados na Faculdade de Medicina de Ribeirão Preto, são revistos, e destacada a importância dos mesmos.

UNITERMOS: Doença de Chagas. Trypanosoma Cruzi. Escolas Médicas. Ribeirão Preto; história.

Doença de Chagas e a Faculdade de Medicina de Ribeirão Preto, a Faculdade, são velhas conhecidas. Essa relação gerou conhecimento novo, alicerçou a reputação da Faculdade e pavimentou a trajetória de carreiras acadêmicas. Deixou, também, lições e exemplos, que merecem ser lembrados.

A Faculdade teve, muito cedo, motivos para reconhecer a doença de Chagas como um problema irrecusavelmente seu. A primeira turma de estudantes ainda não conhecera as enfermarias da Santa Casa, onde o curso de Propedêutica seria ministrado, e o Departamento de Parasitologia já realizava um estudo sobre reservatórios e transmissores do Tripanosoma cruzi, sendo o campo de pesquisa a própria fazenda Monte Alegre. O primeiro gambá foi capturado em abril de 1953, a coleta de "barbeiros" foi iniciada em setembro e, logo, vários exemplares infectados haviam sido identificados. Desse primeiro encontro, face a face, entre a Faculdade e a doença de Chagas, resultou, mais tarde, uma publicação, assinada por Astolfo F. Siqueira, Alvaro E. A. Magalhães \& Sidney M. Rego ${ }^{(1)}$.

A partir de então, por largos anos, doença de Chagas foi um dos grandes temas de pesquisa de vários departamentos, do que dão testemunho as 38 teses que trataram do assunto ao longo dos primeiros vinte anos da FMRP(2).

No âmbito da Parasitologia, uma longa série de pesquisas seguiria o rumo apontado pela primeira. No período compreendido entre 1956 e 1979, o grupo constituído por Mauro Pereira Barretto e seus colaboradores, AF. Siqueira, F. Ferriolli Filho, F.M.A Correa, J.R. Carvalheiro, R. D. Ribeiro, G.K. Funayama, F.M. Belda Netto, L.AR. Fernandes, publicaram 73 artigos sob o título principal "Estudos sobre reservatórios e vetores silvestres do Tripanosoma cruzi". Colaboradores eventuais, nessa série, foram J.L.P. Freitas, H. Soto-Urribarri, S.T. Soto, R.D.R. Albuquerque, J. Prado Jr., G.K.F. Takeda e G.M. Rocha. Essa série relata o estudo sistemático de moradores de grutas, ocos de árvores, frondes de palmeiras e tugúrios outros, recolhidos em sucessivas expedições a diversas localidades da região, o que permitiu caracterizar a tripanossomíase americana como uma zoonose que se perpetua em focos naturais, onde convivem mamíferos e triatomíneos, estes se alimentando do sangue daqueles. Nessas pesquisas,encontra amplo apoio o 
conceito, já entrevisto por Carlos Chagas ${ }^{(3)}$, da infecção chagásica humana como uma extensão eventual da enzootia originalmente envolvendo mamíferos em focos silvestres.

Mas, ainda em 1953, antes mesmo que os resultados do primeiro desses estudos fosse divulgado, chegava ao Departamento de Parasitologia José Lima Pedreira de Freitas.

Lembrar que Pedreira de Freitas dedicava-se ao estudo da doença de Chagas já em 1944 é significativo. Embora Carlos Chagas tivesse sido festejado como uma glória da Medicina brasileira*, sua principal contribuição, há muito, fora relegada a capítulos menores dos compêndios de Parasitologia, daqueles que tratam de doenças tropicais exóticas. Era esse, aliás, o destino reservado à doença pelos adversários de Carlos Chagas, na rumorosa polêmica que se estendeu por um ano, de dezembro de 1922 a novembro de 1923, na Academia Nacional de Medicina. Mas não terá sido apenas o desejo manifesto daquele pequeno grupo a principal razão do olvido da doença de Chagas. Ele se deu porque a agenda da Medicina brasileira era, como é, decidida por quem nutre experiência e aufere prestígio em solares e salões de metrópoles, em cujas paredes triatomíneos nunca pousaram. Tanto que uma das primeiras vozes a questionar a existência da doença de Chagas, já em 1922, foi a de Afranio Peixoto, catedrático de Higiene da Faculdade de Medicina do Rio de Janeiro e figura destacada da elite social da antiga capital ${ }^{* *}$. E que, mais de meio século depois do primeiro relato de Carlos Chagas, em setembro de 1960, um professor, catedrático da Faculdade de Medicina de São Paulo, insistia em defender a idéia de ser um vírus o agente etiológico do megaesôfago e do megacólon endêmicos no país ${ }^{(4)}$.
O certo é que a doença de Chagas permaneceu destituída de importância e ignorada, mesmo nas escolas médicas ${ }^{(5)}$, até o final dos anos 30 , quando relatos de origens diversas, inclusive externas ao Brasil, principiaram a modificar esse panorama ${ }^{(6)}$.

Nesse processo, Pedreira de Freitas fora pioneiro em São Paulo. Em primeiro lugar, ao aperfeiçoar, em colaboração com José de Oliveira Almeida, a técnica de fixação de complemento de Guerreiro e Machado, tornando-a acurada e confiável ${ }^{(7)}$. Segundo, pelo estabelecimento, em Cássia dos Coqueiros, de um campo permanente de pesquisa da doença em seus aspectos clínicos e epidemiológicos. E, ainda, pela participação em iniciativas que levaram os clínicos de São Paulo a reconhecer a doença de Chagas, como as publicações, em 1946, do primeiro caso de cardiopatia chagásica, diagnosticado no então recém-inaugurado Hospital das Clínicas de São Paulo ${ }^{(8)}$ e, em 1949, da ampla pesquisa de aspectos clínicos e epidemiológicos da doença de Chagas; levada a cabo, em Cássia dos Coqueiros, com a participação do professor Jairo Ramos e de seus colaboradores da Escola Paulista de Medicina ${ }^{(9)}$.

Com Pedreira de Freitas chegaram sua competência técnica, sua experiência, sua disciplina de trabalho, sua índole empreendedora e, sobretudo, sua noção de responsabilidade social. O ano de 1953 não terminara e a técnica de reação de fixação de complemento para o diagnóstico da doença já era realizada na Faculdade. Na época, a "prestação direta de serviços à comunidade", ou, simplesmente, "extensão", ainda não granjeara o prestígio que hoje desfruta junto às autoridades acadêmicas brasileiras, e sequer figurava entre os objetivos explícitos da Universidade de São Paulo*** . Mas o pesquisador consagrado, convicto da importância da transmissão da doença de Cha-

* Em 1910, Carlos Chagas foi admitido na Academia Nacional de Medicina extraordinariamente, independentemente da existência de vaga, como reconhecimento pela descoberta da doença que leva o seu nome. Em 1912, recebeu o Premio Schauddin, conferido, na Alemanha, por sua contribuição no campo da Parasitologia, considerada a mais importante entre as realizadas no mundo durante os quatro anos anteriores.

** De acordo com Carlos Chagas Filho, (Meu Pai, Rio de Janeiro: Casa de Oswaldo Cruz - FIOCRUZ, 1993, pag 195), o livro de atas das sessões da Academia Nacional de Medicina, Rio de Janeiro, nas páginas 723 e 724, registra o seguinte trecho do discurso de Afranio Peixoto; em 30 de novembro de 1922, ao receber, como membro honorário daquela agremiação, o dr. Figueiredo Vasconcellos, colega de Carlos Chagas no Instituto de Manguinhos: "Podereis ter achado alguns mosquitos, inventado uma doença rara e desconhecido, doença de que se falasse muito ,mas quase ninguém conhecesse os doentes, encantoada lá num viveiro sertanejo de vossa província, que magnanimamente distribuireis por alguns milhões de vossos patrícios, acusados de cretinos. ...".

*** Os fins da Universidade de São Paulo, definidos no decreto do Governador Armando Salles de Oliveira, que a criou, em 25 de Janeiro de 1934, eram:

(a) promover, pela pesquisa, o progresso da ciência;

(b) transmitir, pelo ensino, conhecimentos que enriqueçam ou desenvolvam o espírito ou sejam úteis à vida;

(c) formar especialistas em todos os ramos da cultura, e técnicos e profissionais em todas as profissões de base científica ou artística;

(d) realizar a obra social da vulgarização das ciências, das letras e das artes por meio de cursos sintéticos, conferências, palestras, difusão pelo rádio, filmes científicos e congêneres. 
gas por transfusão, cuja realidade ele mesmo demonstrara $^{(10)}$, deixou o laboratório para, denodadamente, estabelecer contatos com os bancos de sangue da cidade e da região, oferecendo-lhes a oportunidade de submeter à nova técnica amostras de sangue coletado. Assim, depressa difundiu-se a prática de fazer da negatividade da reação de fixação de complemento para Chagas um pré-requisito formal para a aceitação de doadores.

Nunca será possível saber quantos casos de infecção pelo $T$. cruzi foram evitados por essa iniciativa. Mas parece certo que, sem ela, não teriam sido apenas sete os casos da forma aguda da doença de
Chagas, internados nas Enfermarias de Moléstias Infecciosas e Tropicais do Hospital das Clínicas de Ribeirão Preto, entre 1962 e $1979^{* * * *}$, valendo lembrar que, nesse período, a taxa de positividade da reação de Guerreiro e Machado, em amostras de sangue de doadores, era, em Ribeirão Preto, próxima de $15 \%{ }^{(11)}$.

Até meados de 1954, a Faculdade de Medicina de Ribeirão Preto, inteira, era o que é hoje a sua área básica. Em um tempo de muitos transplantes, em que, na área acadêmica, prospera a idéia de que atividades de interesse imediato da sociedade são apanágio das áreas de aplicação, a memória de Pedreira de Freitas convida à reflexão.

OLIVEIRA RB. The Faculty of Medicine of Ribeirão Preto and Chagas' disease: the early times. Medicina, Ribeirão Preto, 33: 338-340, july/sept. 2000.

ABSTRACT: The studies pioneering the research on Chagas' disease at the Faculdade de Medicina de Ribeirão Preto are reviewed and their importance emphasized.

UNITERMS: Chagas Disease. Trypanosoma Cruzi. Schools Medicine. Ribeirão Preto; history.

\section{REFERÊNCIAS BIBLIOGRÁFICAS}

1 - SIQUEIRA AF; MAGALHÃES AEA \& RÊGO SFM. Inquérito preliminar sobre a moléstia de Chagas em uma fazenda do município de Ribeirão Preto. Rev Bras Malariol Doenças Trop 9: 271-276, 1957.

2 - FACULDADE DE MEDICINA DE RIBEIRÃO PRETO. Universidade de São Paulo. Publicação interna da Seção de Expediente, Ribeirão Preto, setembro de 1971.

3 - CHAGAS C. Sobre um trypanosomo do tatú, Tatusia novemcincta, transmitido pelo Triatoma geniculata, Latr., (1811). Possibilidade de ser o tatú um depositário do Trypanosoma cruzi no mundo exterior. (nota prévia). Brazil Med 26: 305-306, 1912

4 - REZENDE JM. Megaesôfago chagásico (Mal de engasgo) dados históricos sobre o reconhecimento da etiologia. Gastroenterol Contemp 2: 6-15, 1998.

5 - ETZEL E. A singular história dos megas chagásicos. Gastroenterol Endosc Dig (GED) 18: 105-109, 1999.

6 - BRASIL A. Considerações sobre a evolução clínica da doença de Chagas. Rev Assoc Med Bras 16: 57-64, 1970.
7 - PEDREIRA DE FREITAS JL. Contribuição para o estudo do diagnóstico da moléstia de Chagas por processos de laboratório. Tese de Doutorado, Faculdade de Medicina da USP, São Paulo, 1947.

8 - DÉCOURT LV; PEDREIRADE FREITAS JL \& ROMEIRO NETO M. Alterações cardíacas na moléstia de Chagas. Rev Hosp Clin Fac Med São Paulo 1: 37-42, 1946.

9 - RAMOS J; PEDREIRADE FREITAS JL \& BORGES S. Moléstia de Chagas - Estudo clínico e epidemiológico. Arq Bras Cardiol 2: 111-162, 1949

10 - FREITAS JLP; AMATO V; SONNTAG R; BIANCALANA A; NUSSENZWEIG V \& BARRETTO JG. Primeiras verificações de transmissão acidental da moléstia de Chagas ao homem por transfusão de sangue. Rev Paul Med 40: 36-40, 1951.

11 - SALGADO FILHO W; VICHI FL; ROCHA JSY \& ROCHA MG. Diminuição da prevalência da moléstia e cardiopatia chagásica no Hospital das Clínicas de Ribeirão Preto entre 1960 e 1970. Rev Assoc Med Bras 22:237-240, 1976.

Recebido para publicação em 28/03/2000

Aprovado para publicação em 11/07/2000

\footnotetext{
**** Informação do prof. João Carlos da Costa, professor aposentado do Departamento de Clínica Médica da Faculdade de Medicina de Ribeirão Preto.
} 